\title{
ENERGY CONSUMPTION FOR POULTRY EGG INCUBATOR TO SUIT SMALL FARMER
}

\author{
HARB, S. K., Y. A. HABBIB, A. M. KASSEM, AND A. EL RAIES \\ Agricultural Engineering Research Institute, ARC, Dokki, Giza
}

(Manuscript received 10 November 2009)

\begin{abstract}
A small poultry incubator was designed and constructed at the Agricultural Engineering Research Institute. It was fabricated to be very cheep and very simple, so it may be utilized to produce a chick for a small farmer. The incubator was fabricated from local materials like wood, automatic thermostat to maintain the temperature at $37{ }^{\circ} \mathrm{C}$ and an electric heater. The incubator capacity was 60 eggs. During the experiment, the temperature, air velocity inside the incubator, egg surface temperature, and power used were recorded. The main objectives of this research is to calculate the energy needs to produce a chick and develop a mathematical model for the incubator introduced. From the experimental data recorded and calculated, it was found that the heat generated from the electric heater measured as $4.55 \mathrm{kw}$, the heat generated from respiration of embryo calculated as $2.58 \mathrm{kw}$, the heat losses from walls of incubator $0.86 \mathrm{kw}$, the heat losses from the orifices 3.055 $\mathrm{kw}$. The heat which was used to evaporate water $(2.48 \mathrm{kw})$ was calculated as heat losses. Then, the net heat $(2.16 \mathrm{kw})$ and heat rejected $(2.387 \mathrm{kw})$. From the previous data, the cost of chick was 1.68 pounds (including the incubator fabrication, the egg price and cost of heat consumption).
\end{abstract}

\section{INTRODUCTION}

Poultry eggs Incubation to be either by natural or industrial incubation. Natural incubation of the chicken eggs providing a home to heat and control humidity and also turned on from time to time. The hatchery industry credited to natural hatchery where the incubator provides temperature, humidity, ventilation and turning. The incubators industry had been developed and operated in terms of efficiency, capacity and has developed modern hatcheries that operate automatically, and the hatching process became the most important economic factors in poultry industry.

Incubation conditions are the most important factors affecting the hatchability of ostrich eggs. As is known, temperature, humidity, ventilation and turning during the incubation period markedly affect the hatchability of fertile eggs and chick quality. Most dramatic effect of these factors on the hatchability of fertile eggs is temperature.

The temperature experienced by a developing embryo depends on three factors, incubator temperature, ability of heat to pass between the incubator and the embryo and metabolic heat production of the embryo itself (French, 1997). 
The effect of temperature on the hatchability of fertile eggs was investigated by many researchers (Meir and Ar, 1990). The incubation temperature of ostrich eggs under natural conditions was determined to be $36.0^{\circ} \mathrm{C}$ (Swart et al., 1987). Egg temperature varies greatly among the species in natural incubation (Wilson et al., 1979). (Wilson 1991) reported that the increase in temperature during incubation was very critical for chick embryos. Moreover, it was reported that growth was retarded or ceased and the incidence of poor second quality chicks increased as the temperature was raised.

The effects of temperature on embryonic development and duration of incubation period depend on the temperature (low or high), age of the embryo, duration of exposure and their interactions, as well as humidity and type of incubator (Wilson, 1991).

Temperature is a very important factor affecting embryo development hatchability (Deeming and Ferguson, 1991, Wilson, 1991), and post hatch performance (Wilson, 1991).

In incubation trials, air temperature is often used as treatment applied to the eggs (French, 1997). It could be questioned whether internal egg temperature (embryo temperature) would be more relevant than air temperature, because air temperature is not simply equal to embryo temperature and can vary independently (Meijerhof and Van Beek, 1993).

Chicken embryos are poikilothermic, relying on an external source (hen or incubator) to provide heat to develop and maintain normal metabolic functions (Tazawa et al., 1989). Consequently, it is important to incubate eggs at a temperature that optimizes hatchability, which is defined as 37.5 to $37.8^{\circ} \mathrm{C}$. In incubation trials, however, air temperature is often used as the treatment applied to the eggs (French, 1997). The limitation to this approach is that air temperature is not always equal to internal egg temperature and can vary independently (Meijerhof and van Beek, 1993).

Internal egg temperature is the temperature experienced by the embryo, it is therefore more influential on embryonic development and hatchability than air temperature the difficulty in measuring internal egg temperature is that it requires destruction of the eggshell, which can affect embryonic development. Eggshell temperature (EST), therefore, can be used as a nondestructive method of measuring internal egg temperature. In practice, the average EST may be close to $37.8^{\circ} \mathrm{C}$, but deviations of over $4^{\circ} \mathrm{C}$ can be found, depending on location in the incubator and embryonic age (Lourens, 2001). 
The lowest EST readings are often found at the start of incubation in multistage incubators, whereas high EST readings are not uncommon in both single-stage and multistage incubators in the latter part of incubation. Large EST fluctuations have an obvious impact on hatchability and chick quality (Lourens, 2001), but so do slight deviations of less than $1^{\circ} \mathrm{C}$ from $37.8^{\circ} \mathrm{C}$ EST (Lourens et al., 2005). Incubation temperature has been found to affect hatching success and incubation duration (Steyermark and Spotila, 2001, Gutzke and Packard, 1987, Ewert 1979). In addition, incubation temperature can affect the general fitness of the animal. Righting response, or the turtle's ability to flip from being on its carapace to its plastron, is an important behavior because turtles are vulnerable to predators, overheating, and suffocation when inverted on their backs. Since righting is important for survival, it is relevant to fitness, and due to the instinctive nature of righting, they readily perform the behavior. Therefore, we purposed to quantify the righting abilities of juveniles incubated at different temperatures following a similar protocol used by Freedberg et al. (2004), who found that different incubation temperatures do affecting some species' speed in righting.

Most poultry species have an optimum incubation temperature of 37 to $38{ }^{\circ} \mathrm{C}$ and small deviations from this optimum can have a major impact on hatching success and embryo development (Wilson, 1991). The vast majority of poultry hatching eggs are artificially incubated in incubators that must be designed to accurately control the temperature inside the machine to ensure that the temperature of the developing embryo does not deviate from this optimum. The temperature experienced by the developing embryo is dependent on three factors: 1) the incubator temperature, 2) the ability of heat to pass between the incubator and the embryo, and 3) the metabolic heat production of the embryo itself. The purpose of this review is to use a simple thermal energetic model of the artificial incubation process to describe the interrelationships among the three factors that determine embryo temperature and discuss some of the implications for the design of incubators.

The phenotype of an organism is not solely the result of its genotype. Environmental variables can also exert a powerful effect on phenotypic traits, and recent years have seen a growing appreciation of the potential evolutionary significance of this kind of phenotypic plasticity. For example, traits will not evolve (i.e. show long term directional change) even under intense natural selection, if the variance in those traits is engendered by the local environment rather than genetic factors. Given the widespread occurrence of phenotypic plasticity, and its potential influence on the ways in which selective pressures translate into evolutionary shifts, we need a clearer understanding of the nature, magnitude and persistence of 
environmentally-induced modifications to the phenotype. Phenotypic plasticity can operate at any stage of an organism's life history, but its influence during early ontogeny may be of particular importance. Embryogenesis is a crucial stage in the lifehistory of all organisms, but the potential impact of environmental factors is greatest in oviparous (egg-laying) species, where a large proportion of development occurs outside the mother's body. In oviparous reptiles, the incubation conditions experienced during embryogenesis have been shown to influence a wide variety of hatchling traits including size (Gutzke \& Packard, 1987, Van Damme et al., 1992), shape (Burger, 1990), color (Ewart, 1979, Deeming \& Ferguson, 1991), and a suite of behavioral and performance characteristics (Burger, 1989, Van Damme et al., 1992, Janzen, 1993). Reptiles thus offer useful model systems in which to investigate the biological significance of phenotypic plasticity. Although the influence of incubation temperature on hatching reptile morphology is well-documented, the ecological and evolutionary significance of these effects remains obscure. In order to evaluate this issue, information on the magnitude of modifications to the phenotype induced by thermal regimes in natural nests is needed. Thus, measuring actual nest temperatures, and incubate eggs under conditions that encompass the range of natural variation carried out(e.g. among nests within a population, or among seasons, or among years).

\section{INCUBATOR OPERATION}

Temperature - maintain the temperature range between $37-38^{\circ} \mathrm{C}$. if possible. The thermometer used to measure the temperature at a level or slightly above where the center of the egg. Overheating the embryo is much more damaging than is under heating it, overheating speeds up embryo development, lowers the percentage of hatchability, and causes abnormal embryos. Although a short cooling period may not be harmful, longer periods of low temperatures will reduce the rate of embryo development. Excessively low temperatures will kill the embryos. If the temperature remains beyond either extreme for several days, hatchability may be severely reduced.

Humidity - the moisture level in the incubator should be about 50 to 55 percent with an increase to about 65 percent for the last 3 days of incubation. Moisture is provided by a pan of water under the egg tray. The water surface should be at least half as large as the surface of the egg tray. Add warm water to the pan as necessary. If more humidity is needed, increase the size of the pan or add a wet sponge. Humidity adjustment can also be made by increasing or decreasing ventilation.

If a wet bulb thermometer or hygrometer is not available, the size of the air cell in each egg can be used to estimate whether the humidity should be increased or 
decreased (see candling instructions). The air cell increases in size during incubation at a rate that depends on temperature and humidity as moisture evaporates from the egg. Figure (1) shows the normal size of an egg's air cell at 7, 14, and 18 days of incubation.

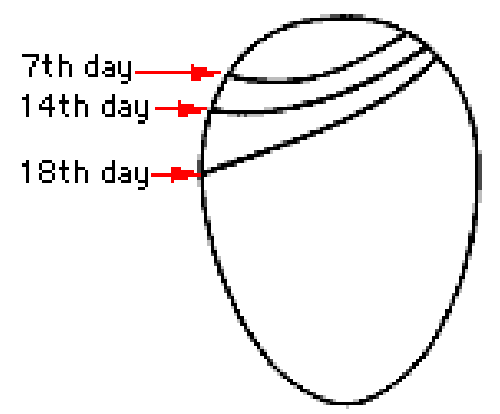

Fig. 1. Size of the air cell in the egg on the 7th, 14th, and 18th day of incubation

Ventilation - is adjusted by increasing or decreasing openings in the sides or top of the incubator. Normal air exchange is needed during embryo development and should be increased as the chicks begin to hatch. The embryo needs oxygen and produces carbon dioxide. However, the correct relative humidity must be maintained until most of the chicks are out of their shells. Do not open the incubator unless necessary during the last 3 days of incubation.

Turning - the eggs should be placed into the incubator on their sides. Turn them at least 3 times a day, except for the last 3 days when they don't need turning. Turn the eggs an odd number of times so the position that is up the longest (at night) will be changed from day to day. Mark the date or an "X" on each egg so you can tell if the eggs have been turned. When you turn the eggs, move them to a different part of the tray to minimize the effects of temperature variation in the incubator. If the eggs are not placed on their sides, they should be placed at an angle so the small ends are in the downward position. Weekends often pose a problem for teachers incubating eggs at school. They sometimes take the incubators home (placing the eggs into egg cartons and wrapping them to keep them warm when traveling back and forth), especially the 1st weekend.

Studies on the effects of incubation temperature on embryo metabolism have been reviewed by Deeming and Ferguson (1991). As temperature changes, so does the oxygen consumption of the embryo and, hence, its heat production, $\mathrm{H}_{\mathrm{emb}}$. Avian embryos for the majority of the incubation time are poikilothermic and therefore do not increase their metabolic heat output to maintain $\mathrm{T}_{\mathrm{emb}}$ when Tinc declines. Indeed, the opposite occurs and as $T_{\text {inc }}$ decreases so does oxygen consumption. Tazawa et al. (1989) showed that at about 18 days of incubation the chick embryo could maintain oxygen consumption when temperature fell from 38 to $35 \mathrm{C}$ but as temperature 
decreased further, oxygen consumption then declined. After pipping, an increase in oxygen consumption in response to a decrease in Tinc has been observed in both chickens (Tazawa et al., 1989) but full thermoregulatory response in Galliformes only develops after hatching.

The temperature experienced by the developing embryo is dependent on the incubator temperature, the metabolic heat production of the embryo, and the thermal conductance of the egg and surrounding air. Studies investigating the effects of temperature on the development and hatchability of poultry embryos have concentrated mainly on the effects of incubator temperature and have ignored the other two factors (N. A. FRENCH, 1997).

The consistency of incubation-induced modifications when measured under different test conditions. Measures of locomotors ability are strongly influenced by test conditions (especially, ambient temperature: e.g. Kaufmann \& Bennett, 1989, Mautz et al., 1992). Although several studies have documented changes in locomotors performance (running or swimming speeds) due to incubation temperatures, all have tested offspring at only one temperature (e.g. Burger, 1989, Van Damme et al., 1992, Janzen, 1993b, Shine \& Harlow, 1993, Shine, 1995). One plausible way in which incubation temperatures might affect organism performance is by means of modifying the animal's thermal 'set-point' for optimal performance (e.g. Burger, 1989), that is, mean overall performance levels are unaffected. Incubation temperatures experienced by reptilian eggs influence many aspects of a hatchling's phenotype. Traits such as size, morphology, locomotors performance, behavior, and sex can all be affected by temperature (Deeming, 2004). Temperature effects during development are assumed to have fitness consequences, but direct empirical evidence to support this assumption has been difficult to come by because the maturation process in many reptiles is slow and so following hatchlings to maturity is often impractical. Laboratory studies have been employed to investigate the effects of incubation temperature on fitness. These studies have primarily utilized constant temperatures and fitness surrogates to estimate the effects of incubation temperature on fitness and report that, in general, increasing incubation temperature results in shorter incubation times and increased locomotors performance in turtles (Janzen, '93, Du and Ji, 2003), whereas elevating temperatures resulted in decreased performance in lizards (Qualls and Andrews, 1999, Bran $\sim a$ and $\mathrm{Ji}, 2000$ ). Studies have also shown that fluctuating incubation temperatures can influence hatchling phenotypes differently than constant temperatures (Shine et al., 1997, Ashmore and Janzen, 2003, Mullins and Janzen, 2006, but see Demuth, 2001), but the phenotypic outcomes vary depending upon experimental conditions including the magnitude of fluctuations (Georges et al., 1994). 
The aim of the research is to estimate the best engineering factors which affected on the small incubator to help the young farmer investment in poultry industry.

\section{THEORY OF HEAT EXCHANGE}

The thermal energetic of incubation have been modeled by Kashkin (1961), Kendeigh 1963), Sotherland et al. (1987), Turner (1991, 1994), and Meijerhof and van Beek (1993). A simple form of the model can be given as :-

$$
\mathrm{T}_{\text {egg }}=\mathrm{T}_{\text {inc }}+\left(\mathrm{H}_{\mathrm{emb}}-\mathrm{H}_{\text {water loss }}\right) / \mathrm{K}
$$

Where:-

$\mathrm{T}_{\text {egg }}=$ temperature of the egg (Celsius),

$\mathrm{T}_{\text {inc }}=$ temperature of incubator (Celsius),

$\mathrm{H}_{\mathrm{emb}}=$ heat production of embryo at a given moment of incubation (watts),

Hwater loss = heat loss from evaporative cooling (watts),

and $\mathrm{K}=$ thermal conductance of egg and surrounding boundary of air around the egg (watts per degree Celsius).

The heat balance of an animal is described by (Schmidt-Nielsen, 1975) as follows:

$$
\mathrm{H}_{\text {emb }}=\mathrm{H}_{\text {water loss }} \pm \mathrm{H}_{\text {rad }} \pm \mathrm{H}_{\text {conv }}
$$

or rewritten,

$$
\mathrm{H}_{\text {emb }}-\mathrm{H}_{\text {water loss }}=\mathrm{H}_{\text {rad }}+\mathrm{H}_{\text {conv }}
$$

where $\mathrm{H}_{\mathrm{rad}}$ and $\mathrm{H}_{\text {conv }}$ are the heat lost or gained by radiation and convection (watts) respectively. Equation (1) uses the terms Hemb $-\mathrm{H}_{\text {water loss }}$ to describe the heat loss or gain from an egg because they are easier to measure than either $\mathrm{H}_{\text {rad }}$ or $\mathrm{H}_{\text {conv }}$. Heat transfer through radiation is assumed to be small because all the surfaces within the machine will be at temperatures close to (within approximately 1 to $2{ }^{\circ} \mathrm{C}$ of) the surface temperature of the egg. Kashkin (1961) estimated that 40 to $45 \%$ of the total heat loss from a duck's eggs was by radiation, however, this estimate has assumed that the total egg surface would be able to radiate heat to the surface of the incubator. In a commercial incubator an egg would be surrounded by other eggs at the same temperature, thereby reducing the effective radiative surface of the egg (Kashkin, 1961). It is therefore assumed that the main transfer of heat occurs through convection. Equation 1 contains the term $H_{\text {water }}$ loss because eggs continually lose water through incubation, typically amounting to $12 \%$ of the fresh egg weight between the onset of incubation and the start of pipping (Ar, 1991). The phase change from liquid water to water vapor requires heat and at incubation temperature this equates to approximately $580 \mathrm{cal} / \mathrm{g}$ of water lost (Schmidt- Nielsen, 1975). For 
example, a 60-g chicken egg loses approximately $0.4 \mathrm{~g}$ of water/d, which equates to a heat loss of $232 \mathrm{cal} / \mathrm{d}$ or $11.2 \mathrm{mw}$. Embryo heat production can be measured directly, but Romijin and Lokhurst (1960) showed that it can be estimated by measuring $\mathrm{O}_{2}$ consumption. Every liter of $\mathrm{O}_{2}$ consumed by the embryo is equivalent to the production of $4.69 \mathrm{kcal}$ of heat (Vleck et al., 1980). Typical $\mathrm{O}_{2}$ consumption of a chicken egg just before pipping is $570 \mathrm{~mL} / \mathrm{d}$ (Vleck and Vleck, 1987), equivalent to heat production of $2.67 \mathrm{kcal} / \mathrm{d}$ or $130 \mathrm{mw}$. At the onset of incubation, Hemb is negligible and therefore Tegg < Tinc because Hemb < Hwater loss. The thermal conductivity term, $\mathrm{K}$, used in Equation 1 combines the thermal conductivity of the egg (Kegg) and the boundary layer of air around the egg $\left(K_{\text {air }}\right)$. Sotherland et al. (1987) determined values for $K_{\text {egg }}$ and $K_{\text {air }}$ and showed that the air boundary layer around the egg was approximately 100 ' greater a barrier to heat loss than the egg itself. These authors also showed that the value of $K_{\text {air }}$ is dependent on the air speed over the eggs and the relationship could be estimated as follows:-

$$
\mathrm{K}=(0.97 \mathrm{~V} 0.6) \mathrm{M} 0.53
$$

where $V=$ air speed (centimeters per second), and $M=$ egg mass (grams). The effect of changing air speed from 0 to 100 or $400 \mathrm{~m} / \mathrm{s}$ increased thermal conductance by approximately $2.5^{\prime}$ and $6^{\prime}$, respectively. A similar relationship was found by Meijerhof and van Beek (1993). An important consequence of the relationship between Kair and air speed is that the differential between Tegg and Tinc during the second half of incubation will become greater at slower air speeds. Meijerhof and van Beek (1993) estimated the increase in Tegg over Tinc for eggs of different weights and Hemb at two air speeds, 0.5 and $2 \mathrm{~m} / \mathrm{s}$. Similarly, it is possible to use the values of $\mathrm{K}$ derived by Sotherland et al. (1987) for air speeds of 0,1 , and $4 \mathrm{~m} / \mathrm{s}$ in Equation 1 to estimate Tegg - Tinc. Figure 3 plots the relationship between air speed and Tegg - Tinc derived from the two studies based on a $50 \mathrm{~g}$ egg with a $\mathrm{H}_{\mathrm{emb}}$ of $100 \mathrm{mw}$. As can be seen, there is good agreement between the estimates of Tegg - Tinc between the two studies.

\section{MATERIALS AND METHODS}

An Incubator for chicken egg was designed, constructed and installed on the Agricultural Engineering Research Institute (AEnRI) Dokki - Giza in order to test, study and evaluate its Engineering performance. The Incubator box gross dimension was 60 $\mathrm{cm}$ long, $50 \mathrm{~cm}$ width and $35 \mathrm{~cm}$ height, it made from plywood $18 \mathrm{~mm}$ thick. The Incubator capacity was 60 eggs (Fig. 2 \&3).

The Incubator box had a mechanical thermostat Fig. (4) to adjust the temperature at the middle of the Incubator to $37^{\circ} \mathrm{C}$, The mechanical thermostat made 
from a bar of iron inside a tube of copper connected with an electric cut off which used in car, behind it iron spring to push one side of electric cut off to touch the other side of it and close the electric heater circuit when the temperature inside the incubator was less than $37^{\circ} \mathrm{C}$ and the copper par contracted. But the spring push the two sides of electric cut off far from each other when the mean temperature inside the incubator arrive to $37^{\circ} \mathrm{C}$ and the copper bar expanded.

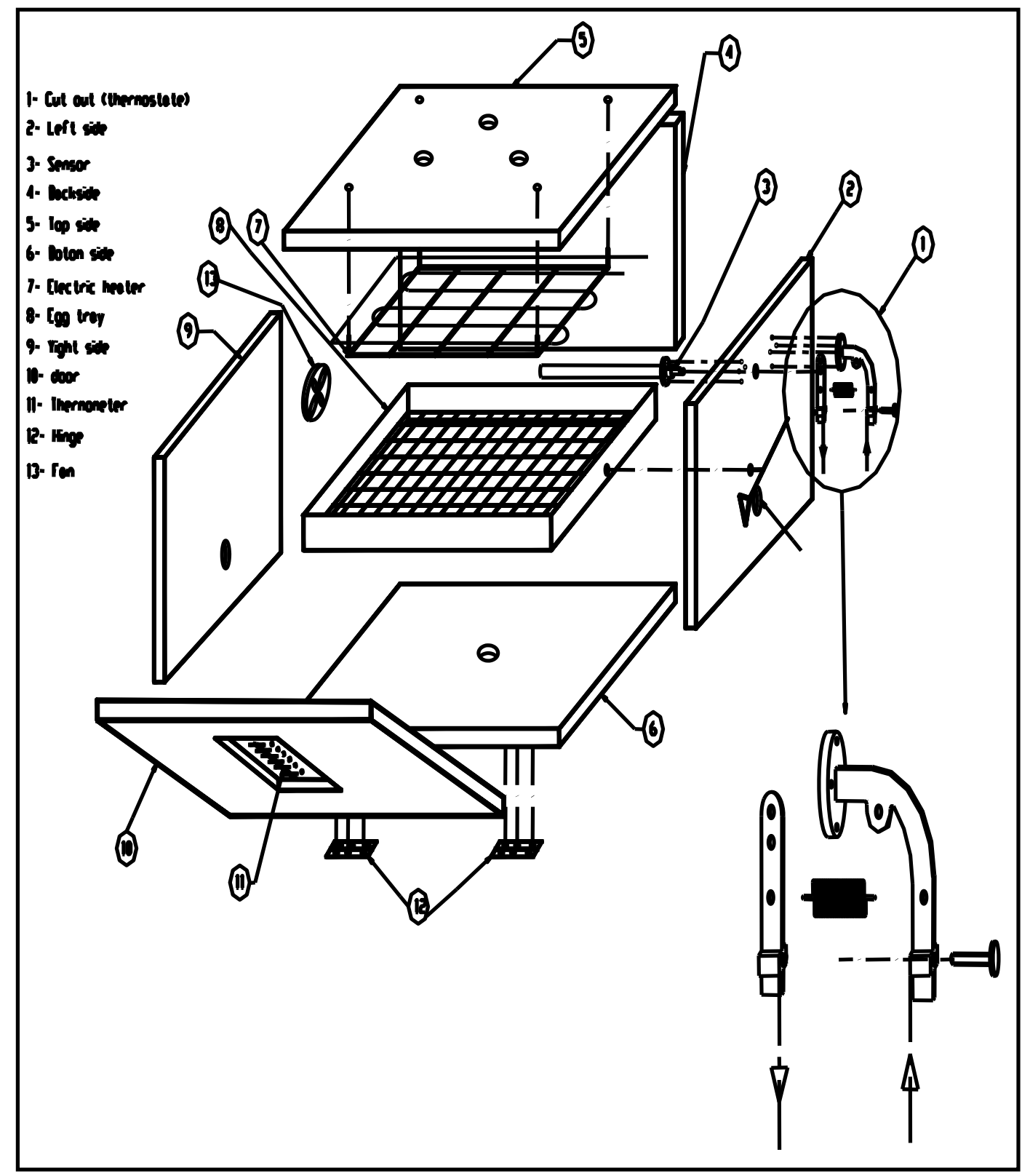

Fig. 2. The designed incubator 

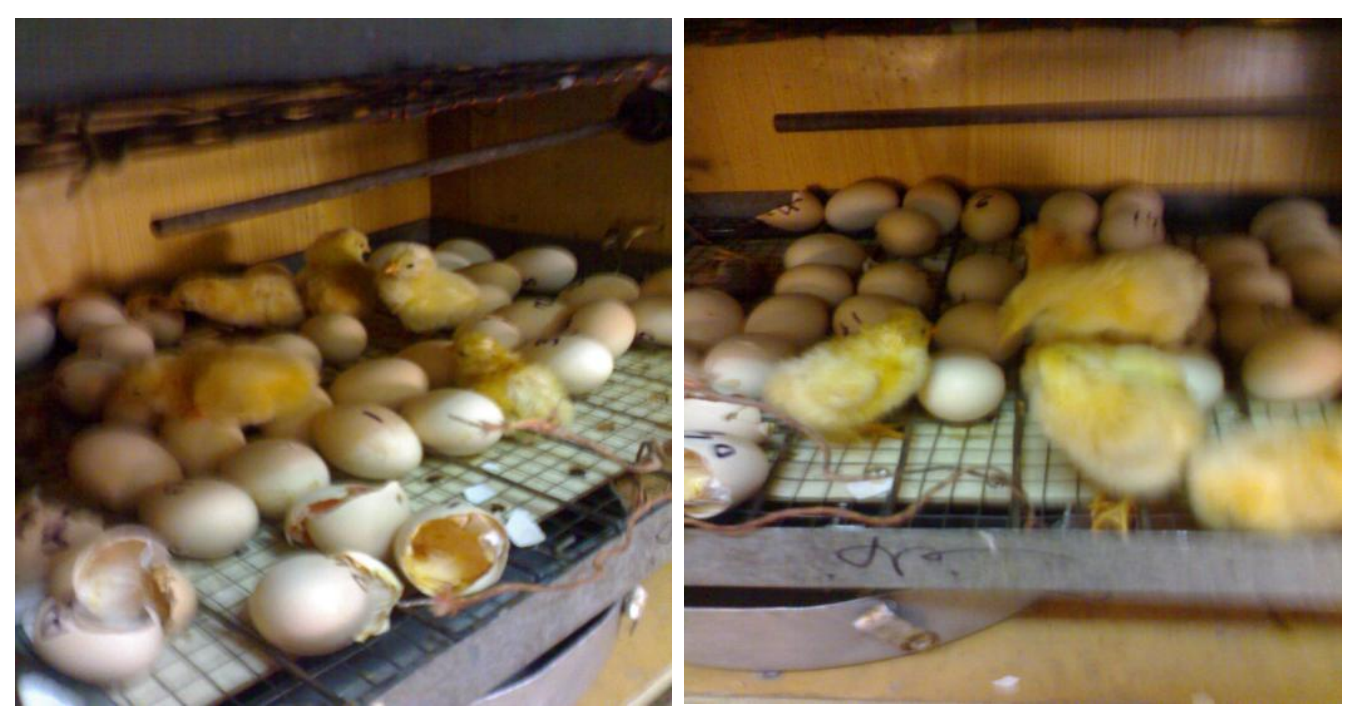

Fig. 3. Hatching in an Incubator

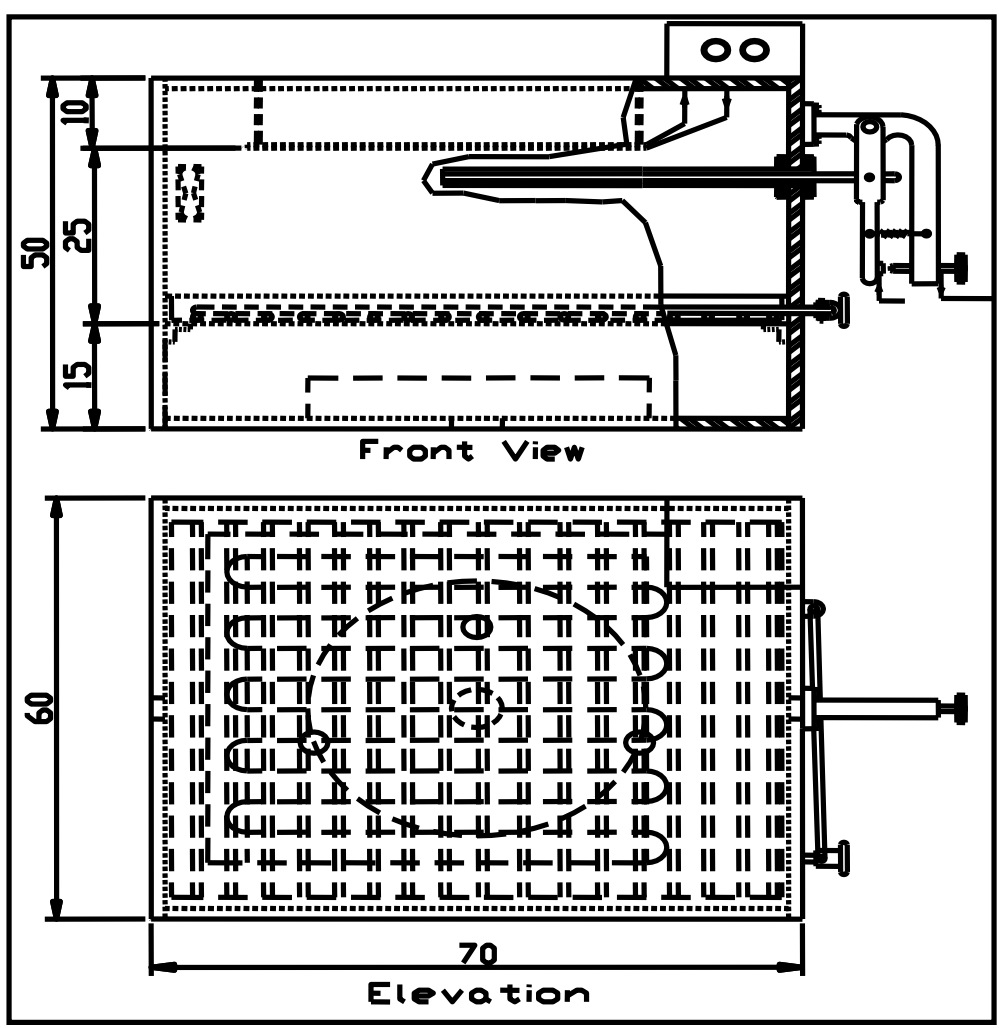

Fig. 4. The Incubator box with a mechanical thermostat 
It also had two shelves, one of it made from Galvanic Iron Sheet (GIS) with real dimension $50 \mathrm{~cm}$ long and $40 \mathrm{~cm}$ width, and the other made from Galvanic Iron Wire (GIW) with $2 \mathrm{~mm}$ diameter, it cut 10 pieces with $40 \mathrm{~cm}$ long and wilted every $5 \mathrm{~cm}$ with a wire frame its gross dimension $50 \mathrm{~cm}$ long and $40 \mathrm{~cm}$ width. The (GIW) shelves slides up on the (GIS) shelves to moving the eggs inside the incubator by free hand fixed outside the Incubator, this moving twice or thee times every day was very important to distribute the temperature at all over the egg surface area.

The incubator had an electric circle box (Fig. 5) to connect the electric heater with the mechanical thermostat to adjust the mean temperature inside the incubator at $37^{\circ} \mathrm{C}$ automatically.

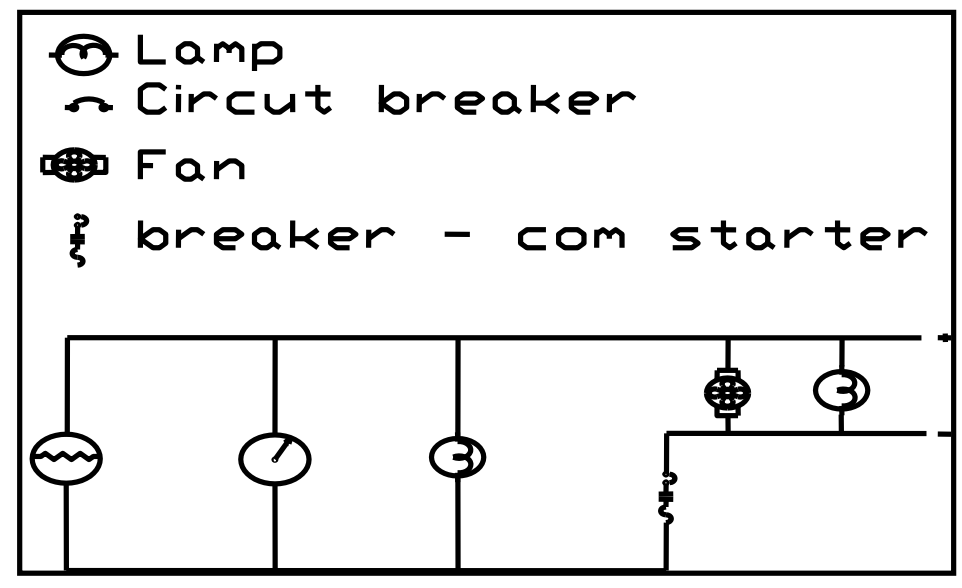

Fig. 5. Operation electric circuit

The incubator had 6 holes with $1.8 \mathrm{~cm}$ diameter, three of them at the top of the incubator one at left side, one at the right side and one at the bottom, to aerate the incubator room, also it had a small fan ( $3 \mathrm{mv}$ current) to move the air inside the incubator, it had also a source of water to raise the relative humidity inside the incubator to $60 \%-65 \%$ during the experimental period.

The meteorological data station, sixteen channels [Consort nv T851, Resolution $<1000{ }^{\circ} \mathrm{C}, \quad 0.1{ }^{\circ} \mathrm{C}\left(0.1{ }^{\circ} \mathrm{F}\right)$ Digital output, Programmable RS 232, 1500 --- $4800 \mathrm{~b} / \mathrm{s}$, for bi-directional communication with computer or printer] which installed just above the incubator to measure the dry and wet temperature by thermocouples (type E ) at 9 points inside and outside the incubator which used. Three thermocouples used to measure the dry temperature inside the incubator, two thermocouples used the measure the egg surface temperature at the bottom and the top, one thermocouple used to measure the wet temperature inside the incubator, one thermocouple used to measure outside air temperature and two thermocouples used to measure the air temperature which bushed outside the incubator through the aeration holes. 


\section{RESULTS AND DISCUSSION}

During experimental work all the Engineering properties has been installed inside the incubator such as the optimum temperature $\left(35\right.$ to $\left.37^{\circ} \mathrm{C}\right)$, turning the eggs (Two or three times per day), ventilation (through special 6 holes with $1.8 \mathrm{~cm}$ diameter distributed around the incubator, three of them are at the top of the incubator one at left side, one at the right side and one at the bottom) and relative humidity was $52 \%$ during the test.

This was a problem during the experiment. This value is very low compared with the optimum value which is recommended. For that, the incubator must be redeveloped to increase the relative humidity.

Data obtained by the researchers indicated that the temperature applied during the growth period in artificial incubation of chicken eggs during incubation durations was $35-37^{\circ} \mathrm{C}$, There was a clear linear relationship between incubation duration time and incubation outside and inside temperature (Figure 6).

From figure (6), it found that the growth temperature was less than the maximum temperature inside the incubator, therefore found the effects of temperature on embryonic development and duration of incubation period depend on the temperature (low or high), then the embryonic development was late than 21 days but it was produce about $82.6 \%$ from the all eggs inside the incubator (46 eggs).

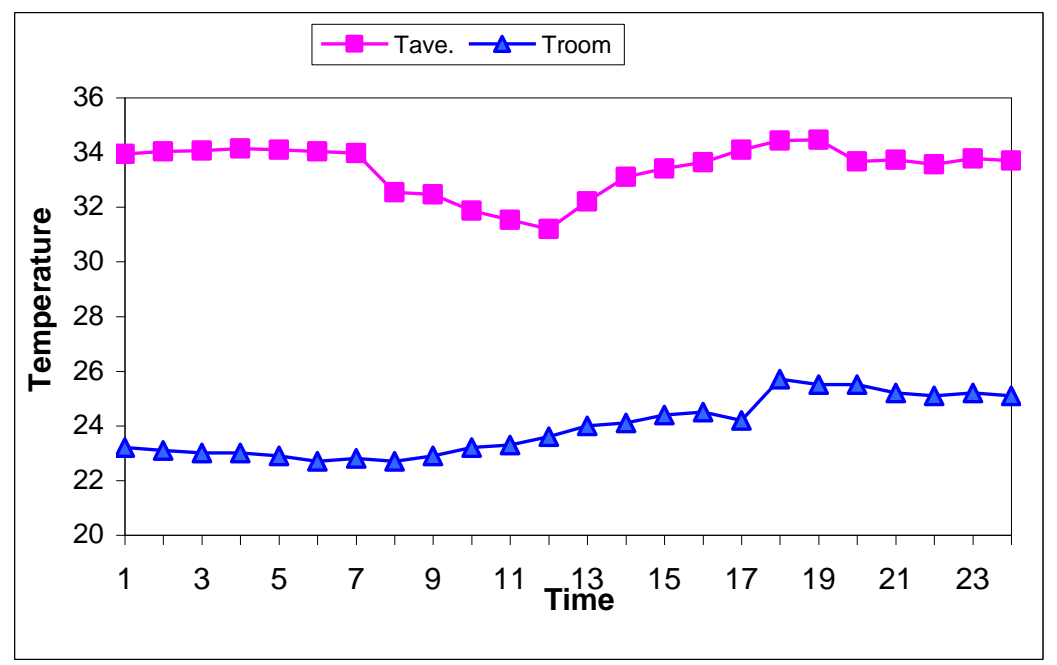

Fig. 6. The relationship between the time and the temperature inside $\&$ outside incubator 
It was clear that the incubator during the experimental work was very economic for energy consumption during the spawning. Therefore, the amount of energy during incubation durations was $320.5 \mathrm{w}$ h as shown as at the next figure (7)

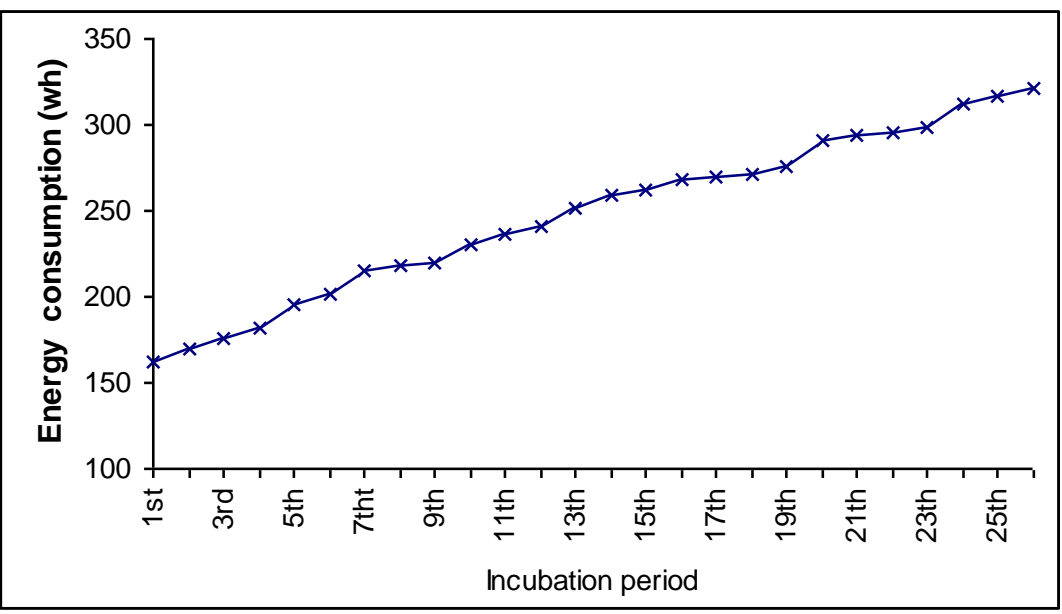

Fig. 7. Energy consumption during the incubation durations

Figure (8) show the amounts of relative humidity during the period of experiment. The figure indicate that the relative humidity is very low than the all references said. For that, the incubator must be developed and the source of relative humidity to increase it until $55 \%$ during the incubation and $65 \%$ during the spawning. For that reason the relative humidity affected to the spawning percentage.

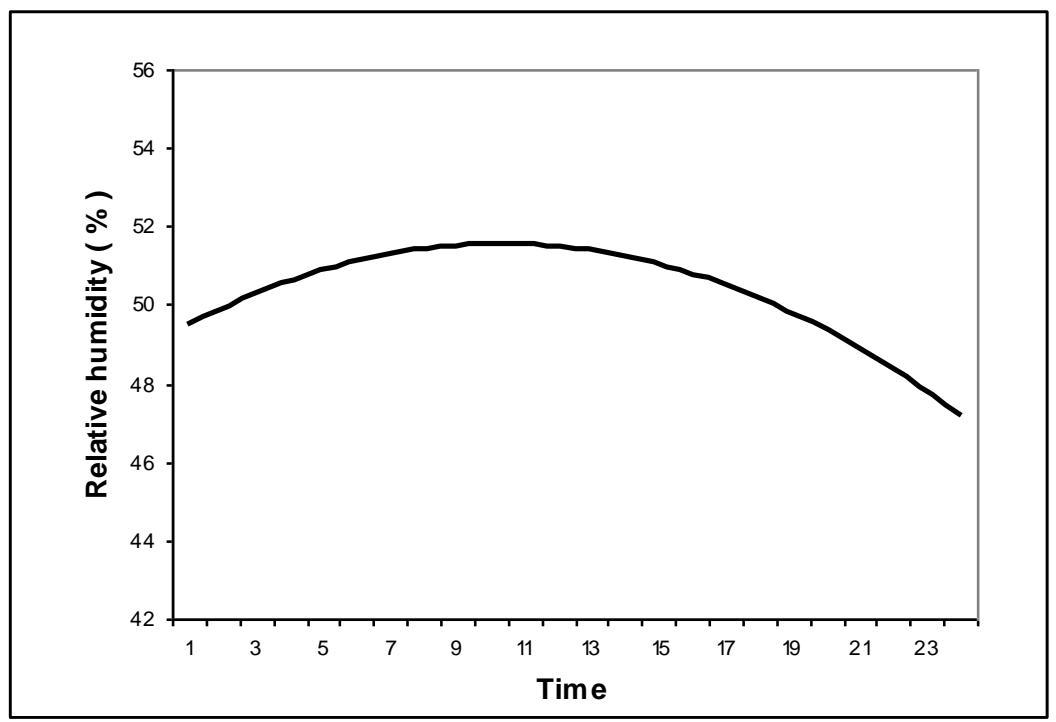

Fig. 8. Relative humidity during the incubation. 
Figure (9) show that the quantity of heat resulted by using the electric heater and the heat generated by respiration of embryo $\left(Q_{i n}\right)$. In addition, the heat losses from the conduction and convection from the walls of incubator ( $Q_{\text {out }}$ ). Moreover, all of heat losses from evaporating water which use to increase humidity inside the incubator, and the heat loses from the orifice which use to exited the air from the inside incubator to outside. The net heat inside incubator $\left(Q_{n e t}\right)$ resulted from the heat generated and the heat losses.

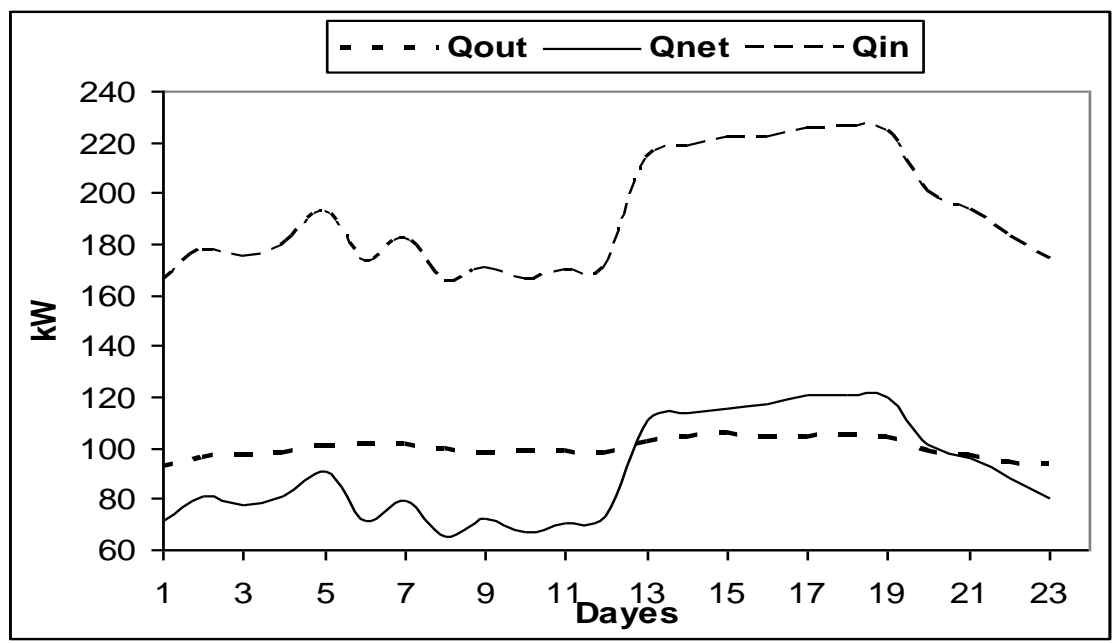

Fig. 9. Incubator hear balance

From the collected data, expected equation to estimate the temperature in incubator is as follows:-.

$$
T_{\text {egg }}=9.078 T_{\text {in }}-1.84\left(H_{\text {emb }}-H_{\text {water }}\right) / K
$$

The previous equation meant that the temperature of egg inside the incubator effected with the temperature of incubator, the heat generated from the embryo, and evaporate the water inside the egg. From the data collection, the correlation factor $\left(R^{2}\right)$ of this equation is $97 \%$. The equation illustrated that the temperature of egg inside incubator was less than the temperature inside the incubator. The term of equation that explains heat balance inside the egg has big effect on the temperature of egg inside the incubator.

The total cost can be estimated from the cost of power generated from the heater and the power calculated from the measurement of electricity. The power estimated that $2.16 \mathrm{~kW}$ at the end of experiment. The price of electricity was $0.11 \mathrm{~L}$.E. Then the total cost for the experiment was 23.755 pound. The experiment produced 45 chickens. The electric cost of per chicken was 0.53 pound.

The price of incubator was 70 pound as a fixed cost, and then the cost of one small chicken was 1.68 L.E. according to 2009 price. 


\section{REFERENCES}

1. Ashmore GM., FJ. Janzen. 2003. Phenotypic variation in smooth soft shell turtles (Apalone mutica) from eggs incubated in constant versus fluctuating temperatures. Oecologia 134:182-188.

2. Braña F., Ji X. 2000. Influence of incubation temperature on morphology, locomotor performance, and early growth of hatchling wall lizards (Podarcis muralis). J Exp Zool 286: 422-433.

3. Burger J. 1989. Incubation temperature has long-term effects on behavior of young pine snakes (Pituophis melanoleucus). Behavioral and Ecological Sociobiology 24: 201-207.

4. Deeming, D. C. and M.W.J. Ferguson. 1991. Physiological effects of incubation temperature on embryonic development in reptiles and birds. Chapter 10. Pages 147-172 in: Egg Incubation. D. C. Deeming and M.W.J. Ferguson, ed. Cambridge University Press, Cambridge, UK.

5. Deeming DC. 2004. Reptilian incubation: environment, evolution and behaviour. Nottingham: Nottingham University Press. 349p.

6. Demuth JP. 2001. The effects of constant and fluctuating incubation temperatures on sex determination, growth, and performance in the tortoise Gopherus polyphemus. Can J Zool 79:1609-1620

7. Du W-G, Ji X. 2003. The effects of incubation thermal environments on size, locomotor performance and early growth of hatchling soft-shelled turtles, Pelodiscus sinensis. J Therm Biol 28:279-286.

8. Ewert, MA. 1979. The embryo and its egg: development and natural history. Harless M, Morlock H (eds) Turtles: perspectives and research. Wiley, New York, pp 333-413

9. Freed berg, S., AL Stumpf, MA Ewert and CE Nelson. 2004. Developmental environment has long-lasting effects on behavioral performance in two turtles with environmental sex determination. Evolutionary Ecology Research 2004(6):739747.

10. French N.H. 1997. Modeling incubation temperature: the effects of incubator design, embryonic development and egg size. Poultry Sci., 76, 124-133.

11. Georges A., C., Limpus and R.Stoutjesdijk 1994. Hatchling sex in the marine turtle Caretta caretta is determined by proportion of development at a temperature, not daily duration of exposure. J Exp Zool 270:432-444.

12. Gutzke, WH. and GC. Packard. 1987. The influence of temperature on eggs and hatchlings of Blanding's turtles, Emydoidea blandingii. Journal of Herpetology 21(2): 161-163. 
13. Janzen FJ. 1993. An experimental analysis of natural selection on body size of hatchling turtles. Ecology 74:332-341.

14. Janzen FJ. 1993b. The influences of incubation temperature and family on eggs, embryos, and hatchlings of the smooth softshell turtle (Apalone mutica). Physiological Zoology 66: 349-373.

15. Kashkin, V. V. 1961. Heat exchange of bird eggs during incubation. Biophysica 6:57-63.

16. Kendeigh, S. C. 1963. Thermodynamics of incubation in the House wren, Troglodytes aedon. Pages 884-904 in: Proceedings of the XIIIth International Ornithological Congress, Ithaca, NY.

17. Kaufmann JS. AF. Bennett. 1989. The effect of temperature and thermal acclimation on locomotor performance in Xantusia vigilis, the desert night lizard. Physiological Zoology 62: 1047-1058.

18. Lourens, A. 2001. The importance of air velocity in incubation. World Poult. $17: 29-30$.

19. Lourens, A., H. van den Brand, R. Meijerhof and B. Kemp. 2005. Effect of eggshell temperature during incubation on embryo development, hatchability and posthatch development. Poult. Sci. 84:914-920.

20. Qualls CP. and RM. Andrews. 1999. Cold climates and the evolution of viviparity in reptiles: cold incubation temperatures produce poor-quality offspring in the lizard, Sceloporus virgatus. Biol J Linn Soc 67:353-376.

21. Mautz WJ., CB. Daniels and AF. Bennett. 1992. Thermal dependence of locomotion and aggression in a xantusiid lizard. Herpetologica 48: 471-479.

22. Meijerhof, R. and G. van Beek. 1993. Mathematical modelling ofn temperature and moisture loss of hatching eggs. J. Theor. Biol. 165:27-41.

23. Meir M., Ar A. 1990. Gas pressures in the air cell of the ostrich egg prior to piping as related to oxygen consumption, eggshell gas conductance and egg temperature. Condor, 92, 556-563.

24. Meijerhof, R. and G. van Beek. 1993. Mathematical modeling of temperature and moisture loss of hatching eggs. J. Theor. Biol. 165:27-41.

25. Mullins MA., FJ. Janzen. 2006. Phenotypic effects of thermal means and variances on smooth soft shell turtle (Apalone mutica) embryos and hatchlings. Herpetologica 62: 27-36.

26. FRENCH, N. A. 1997. Modeling Incubation Temperature: The Effects of Incubator Design Embryonic Development, and Egg Size. Poultry Science 76:124-133

27. Romijin, C. and W. Lokhorst. 1960. Foetal heat production in the fowl. J. Physiol. $150: 239-249$ 
28. Schmidt-Nielsen, K. 1975. Animal Physiology. Cambridge University Press, New York, NY.

29. Shine R. and PS. Harlow. 1993. Maternal thermoregulation influences offspring viability in a viviparous lizard. Oecologia 96: 122-127.

30. Shine R. 1995. A new hypothesis for the evolution of viviparity in reptiles. American Naturalist 145: 809-823.

31. Shine R., MJ., Elphick and PS. Harlow. 1997. The influence of natural incubation environments on the phenotypic traits of hatchling lizards. Ecology 78:2559-2568.

32. Sotherland, P. R., J. R. Spotila and C. V. Paganelli. 1987. Avian eggs: Barriers to the exchange of heat and mass. J. Exp.Zool. Suppl. 1:81-86.

33. Steyermark, AC. and JR. Spotila. 2001. Effects of maternal identity and incubation temperature on hatching and hatchling morphology in snapping. Copeia (1): 129135.

34. Swart D., H., Rahn and J. De Kock. 1987. Nest microclimate and incubation water loss of eggs of the African ostrich (Struthio camelus var. domesticus). J. Exp. Zool., 1, 239-246.

35. Tazawa, H., A. Okuda, S. Nakazawa and G. C. Whittow. 1989. Metabolic responses of chicken embryos to graded, prolonged alterations in ambient temperature. Comp. Biochem. Physiol. A Physiol. 92:613-617.

36. Van Damme R., D. Bauwens, F. Brana and RF. Verheyen. 1992. Incubation temperature differentially affects hatching time, egg survival and sprint speed in the lizard Podarcis muralis. Herpetologica 48: 220-228.

37. Vleck, C. M., D. Vleck and D. F. Hoyt. 1980. Patterns of metabolism and growth in avian embryos. Am. Zoologist 20:405-416.

38. Vleck, C. M. and D. Vleck. 1987. Metabolism and energetics of avian embryos. J. Exp. Zool. Suppl. 1:111-126.

39. Wilson H.R., E.R. Miller, T.B. Ande and D.R. Ingram. 1979. Hatchability of bobwhite quail eggs incubated in various temperature combinations. Poultry Sci., $58,1352$.

40. Wilson, H. R. 1991. Physiological requirements of the developing embryo: Temperature and turning. Chapter 9. Pages 145-156 in: Avian Incubation. S. G. Tullett, ed. Butterworth-Heinemann, London, UK. 


\section{الطاقة المستهلكة لمفرخة بيض دواجن تناسب المزارع الصغير}

سمير قرني حرب يسرى أحمد حبيب ، أحمد محم قاسم عبد الرحمن الريس

$$
\text { معهز بحوث الهندسة الزراعية - مركز البحث الزراعية - الدقى - الجبزة }
$$

تم تصميم وتجهيز مفرخ دجاج صغير رخيص و بسيط بمعهد بحوث الهندسة الزر اعية كي

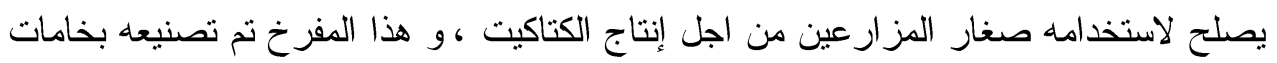
محلية تتكون من خشب و سخان كهربي وثرموستات حراري لحفظ درجة حرارة المفرخ دائما عند

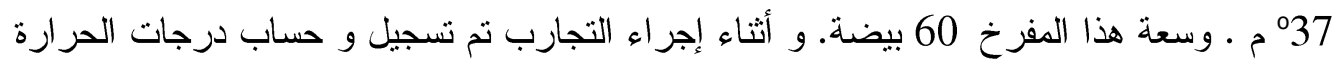

الجافة و الرطبة داخل و خارج المفرخة و تسجيل سرعة الهو اء داخل المفرخة و تسجيل درجة ولهد

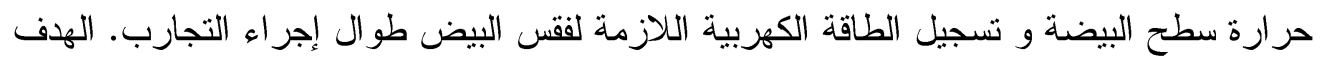

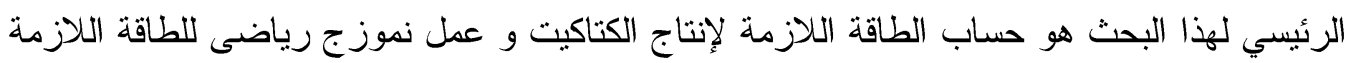

للمفرخ لخدمة صغار المز ارعين ـ من البيانات التى تم تسجيلها وحسابها وجد أن الطاقة الكلية

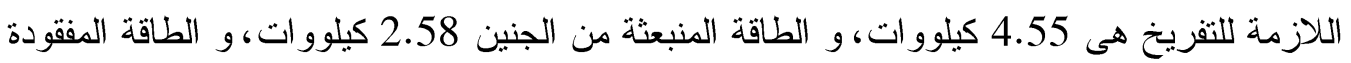
من الحوائط المصنع منها المفرخة 0.86 كيلووات، و الطاقة المفقودة من فتحات التهوية 3.055 كيلووات، و الطاقة اللازمة لتبخير المياه للحفاظ على مسنوى الرطوبة داخل المفرخة 2.48

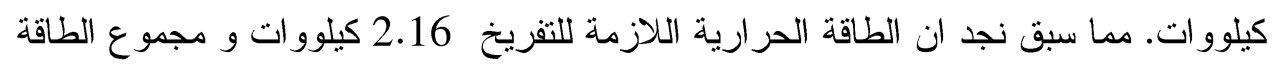
المفقودة 2.387 كيلوو ات ـ و تكلفة انتاج الكتكوت 1.68 جنيه مصرى (شاملا نكاليف صناعة المفرخة الخشبية و السخان الكهربى و الثرموستات و البيض المستخم فى عملية الفقس). 